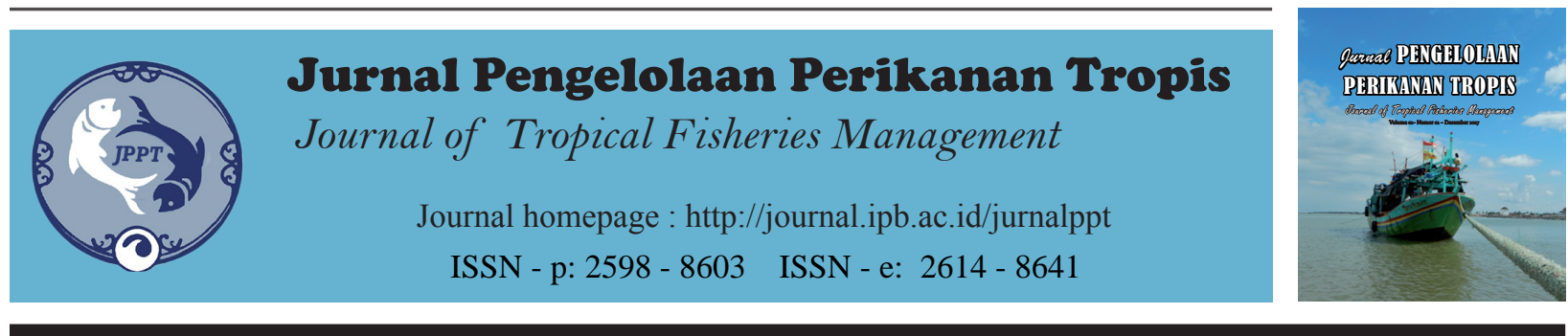

\title{
Distribusi Spasial Kelimpahan Sumberdaya Ikan di Perairan Selat Sunda
}

\author{
(Spatial Distribution of Fish Abundance in Sunda Strait)
}

Surya Gentha Akmal ${ }^{1}$, Achmad Fahrudin ${ }^{1}$, Syamsul Bahri Agus ${ }^{2}$

\begin{abstract}
ARTIKEL INFO
Article History

Received : 20 November 2017

Accepted : 24 Desember 2017

Kata kunci:

Kelimpahan, pemetaan, penyajian, potensi, SIG

\section{Korespondensi Author}

1 Departmen Manajemen Sumberdaya Perairan, Fakultas Perikanan dan Ilmu Kelautan, Institut Pertanian Bogor. J1. Agatis, Kampus IPB Dramaga, Bogor, Jawa Barat, Indonesia. email: sgakmal@apps.ipb.ac.id

2 Departemen Ilmu dan Teknologi Kelautan, Fakultas Perikanan dan Ilmu Kelautan, Institut Pertanian Bogor. Jl. Agatis, Kampus IPB Dramaga, Bogor, Jawa Barat, Indonesia
\end{abstract}

\begin{abstract}
ABSTRAK
Sistem Informasi Geografis (SIG) merupakan salah satu sistem informasi yang sedang berkembang pesat saat ini dan banyak dimanfaatkan untuk analisis dan pemetaan sumberdaya alam, termasuk di dalamnya melakukan penyajian data potensi perikanan berbasis data spasial. Tujuan penelitian ini, yaitu menyajikan analisis hasil survei akustik dalam pendugaan potensi perikanan dengan menggunakan Sistem Informasi Geografis. Pengambilan data di lapangan dilakukan pada bulan Mei hingga Agustus 2013. Pada Bulan Mei, nilai fluktuasi kelimpahan ikan terbesar terdapat pada kedalaman 64-84 m diikuti oleh kedalaman 4-24 m, sedangkan kelimpahan ikan dengan nilai terkecil terdapat pada kedalaman 44-64 m. Fluktuasi kelimpahan ikan pada bulan Juni menggambar-kan rata-rata kelimpahan terbesar pada kedalaman 4-24 m, kemudian nilai rata-rata kelimpahan terkecil terdapat pada kedalaman 64-84 m. kemudian, fluktuasi kelimpahan ikan pada bulan Juli terlihat bahwa kelimpahan terbesar berada pada kedalaman 4-24 m sebesar 19167 ikan/1000m³. Ratarata sebaran kelimpahan ikan bulan Agustus, kelimpahan rata-rata sebesar $3114 \mathrm{ikan} / 1000 \mathrm{~m}^{3}$ dengan kategori melimpah. Hampir seluruh wilayah yang di survei dengan metode akustik cocok dijadikan sebagai wilayah penangkapan.
\end{abstract}

\section{PENDAHULUAN}

SIG merupakan salah satu sistem informasi yang sedang berkembang pesat saat ini dan banyak dimanfaatkan untuk analisis dan pemetaan sumberdaya alam, termasuk di dalamnya melakukan penyajian data potensi perikanan berbasis data spasial. Star dan Estes (1990) mengemukakan bahwa pengembangan SIG dilandasi oleh dua faktor penting, yaitu 1) suatu keinginan untuk pengelolaan lingkungan perkotaan terutama dalam kaitannya dengan perencanaan peremajaan (renewal), 2) suatu keinginan untuk mengembangkan kompetisi penggunaan sumberdaya lingkungan. SIG banyak digunakan karena kemampuannya menyajikan informasi secara lengkap, akurat, murah, dan mudah diakses.
Hasil survei tidak hanya dapat dipetakan secara spasial dengan SIG saja, tetapi dapat juga di gabung dengan berbagai informasi penunjang lainnya sehingga mampu memberikan gambaran dan analisis pendahuluan wilayah perairan secara cepat dan lengkap. SIG dapat digunakan untuk inventaris, analisis, modeling, dan pengelolaan lingkungan sumberdaya alam (Goodchild 1993). Penggunaan teknologi ini didasarkan pada pentingnya hasil perhitungan secara statistik dan hasil survei akustik untuk dapat dinikmati oleh masyarakat luas melalui penyajian data yang mudah diakses dan mampu memberikan informasi lengkap, termasuk analisis kelimpahan secara spasial.

Potensi perikanan merupakan salah satu faktor penting yang perlu dikaji sebagai dasar penentu stok perikanan di suatu perairan. Namun, 
pengkajian potensi perikanan setiap wilayah belum dilakukan secara menyeluruh sehingga data potensi perikanan yang tersedia belum menggambarkan seluruh potensi perikanan di Indonesia. Selain itu, data potensi perikanan wilayah masih disajikan dalam bentuk data statistik sehingga belum tentu dapat dipahami oleh semua kalangan. Oleh karena itu, perlu dilakukan pengkajian dan penyajian potensi perikanan suatu wilayah dengan mentransformasi data statistik yang dilengkapi dengan data survei akustik ke dalam bentuk peta sehingga diharapkan mampu dipahami dengan mudah oleh semua kalangan. Salah satu bentuk penyajian potensi perikanan wilayah dalam bentuk peta adalah dengan melibatkan Sistem Informasi Geografis (SIG).

Pendugaan sumberdaya ikan dari data survei akustik maupun data hasil tangkap, telah banyak dilakukan, terutama oleh para peneliti dalam memperkirakan besarnya stok ikan yang bisa dimanfaatkan di suatu perairan. Hasil analisis tersebut belum sepenuhnya dimanfaatkan secara optimal sebagai sumber informasi yang bermanfaat bagi masyarakat. Data yang didapat dari hasil survei akustik maupun metode hasil tangkap dapat di manfaatkan dalam bentuk informasi yang bereferensi geografis dengan teknologi SIG. Wilayah perairan Selat Sunda memiliki keunikan tersendiri karena merupakan daerah percampuran massa air dari Samudra Hindia dan Laut Jawa. Pada perairan Selat sunda, telah banyak dilakukan penelitian dalam menduga dan menganalisis sumberdaya ikan dan potensi perikanan yang ada di perairan tersebut.

\section{METODOLOGI}

\section{Lokasi Penelitian}

Lokasi penelitian dilakukan di perairan Selat Sunda dengan data yang diolah dan dianalisis berupa data sekunder hasil survei akustik di wilayah perairan Selat Sunda. Pemrosesan data spasial dengan SIG dilakukan di Laboratorium Model dan Simulasi (Lab. MOSI), Divisi Manajemen Sumberdaya Perikanan (Div. MSPi), Departemen Manajemen Sumberdaya Perairan, FPIK-IPB. Pengambilan data di lapangan dilakukan pada bulan Mei hingga Agustus 2013. Analisis data dilakukan pada bulan Januari 2015 hingga bulan Maret 2015.

\section{Prosedur Pengumpulan Data}

Analisis fluktuasi kelimpahan dan potensi perikanan, serta penentuan prioritas wilayah penangkapan berdasarkan data akustik. Data yang dipakai dalam penelitian ini adalah data sekunder yang diperoleh dari data riset DISHIDROS TNI AL (2013) berupa: 1) data kelimpahan ikan, 2) data potensi perikanan, 3) peta perairan Selat Sunda, dan 4) posisi titik perekaman data dari trek pengambilan data akustik setiap satuan jarak pengamatan. Survei akustik dari riset tersebut mengumpulkan data kelimpahan ikan pada 4 strata kedalaman, yaitu strata $1(4-24 \mathrm{~m})$, strata 2 (24-44 m), strata $3(44-64 \mathrm{~m})$, dan strata 4 (64-84 m). Stasiun pengambilan data berjumlah 29 stasiun pada bulan Mei, 35 stasiun pada bulan Juni, 39 stasiun pada bulan Juli, dan 31 stasiun pada bulan Agustus dengan ESDU 6 mil laut.

\section{Penyusunan Basis Data}

Menurut Nurwadjedi (1996), basis data merupakan kumpulan satu atau lebih file data atau tabel yang disimpan secara terstruktur sedemikian rupa sehingga hubungan keterkaitan antara item yang berbeda atau kumpulan data yang berbeda dapat digunakan untuk tujuan manipulasi dan penyajian kembali (retrieval) dan secara umum akan melayani ketersedian data dari berbagai pengguna. Secara garis besar, Nurwadjedi (1996) membagi basis data ke dalam tiga model yang dibentuk dari data spasial yaitu model basis data hierarki, model basis data jaringan (network) dan model basis data relasional. Nurwadjedi (1996) menyatakan bahwa perancangan basis data dengan menggunakan SIG terdiri atas: 1) data yang digunakan mempunyai sistem georeferensi, 2) dalam membangun basis data spasial perlu diperhatikan batas-batas kesalahan yang diperbolehkan agar topologi dapat dibangun secara tepat, 3) menggunakan model data relasional untuk merancang basis data, 4) mendefinisikan field data atribut secara benar, 5) apabila dimungkinkan, setiap field data atribut perlu dirumuskan dengan benar, dan 6) setiap variabel untuk kepentingan manipulasi data harus terwakili dalam basis data.

Pengelolaan data dalam SIG harus didukung oleh fasilitas pengelolaan basis data yang dikenal sebagai Data Base Management System (DBMS) agar berfungsi sebagai sistem informasi. DBMS ini berperan penting dalam manipulasi, analisis, dan penyajian data spasial. Nurwadjedi (1996) mendefinisikan DBMS sebagai paket perangkat lunak untuk penyimpanan, manipulasi, dan penyajian data. Salah satu perangkat lunak yang banyak dikenal adalah software ArcGIS. Pembuatan peta-peta tematik secara digital dilakukan dalam SIG. Data spasial yang didigitasi terdiri atas peta 
Selat Sunda, dan titik-titik koordinat posisi stasiun pengambilan data akustik.

\section{Digitasi}

Proses digitasi yang dilakukan pada penelitian ini adalah menggunakan metode digitasi secara on-screen digitizing sehingga membutuhkan scanner peta yang sudah tergeoreferensi. Proses digitasi memegang peranan penting dalam pemeta-an digital karena melalui tahap inilah data (kenampakan di peta/bentuk analog) dipindahkan dalam bentuk digital.

2. Membuat data spasial

Membuat data vektor dari data raster kemudian disimpan dalam bentuk shapefile (*.shp) dapat dilakukan dengan ArcGIS karena sudah dilengkapi dengan fasilitas on-screen digitizing. Proses ini diawali dengan mendigitasi data raster yang sudah tergeoreferensi.

3. Editing vektor dan atribut

Sering kali kita melakukan proses editing dalam penanganan data spasial, khususnya data vektor dan data atribut, baik dalam rangka updating data maupun memperbaiki data yang telah ada. ArcGIS dilengkapi dengan sejumlah modul editing yang terdapat pada menu Edit untuk melakukan proses updating data serta memperbaiki data vektor dan atribut yang telah ada.

\section{Analisis Data}

SIG dapat menyajikan informasi spasial maupun nonspasial secara bersamaan (Gambar 2). SIG dapat dilakukan dengan memanfaatkan perangkat lunak, seperti ArcGIS sehingga akan memudahkan dalam pemetaan wilayah-wilayah yang bisa dijadikan prioritas untuk penangkapan. Peta dasar diperoleh dari DISHIDROS TNI-
AL tahun 2004. Selain menyediakan fasilitas manajemen data, ArcGIS juga menyediakan fasilitas untuk analisis data termasuk untuk analisis statistik sederhana. Hal ini akan memudahkan pengguna dalam menganalisis data sehingga dapat menghasailkan informasi yang bermanfaat, seperti grafik dan label dari data atribut.

Pada penelitian ini, pemetaan prioritas penangkapan disesuaikan dengan kemampuan tangkap nelayan tanpa membatasi atau menentukan jenis ikan yang ditangkap. Berdasarkan kemampuan armada tangkap nelayan, digunakan data kelimpahan ikan pada ke dalaman $<50 \mathrm{~m}$, yaitu strata 1 (4-24 m) dan strata (24-44 m). Dalam memetakan wilayah untuk suatu area penangkapan, nilai kelimpahan pada tiap stasiun diklasifikasikan berdasarkan kedekatan nilai kelimpahan ikan pada strata 1 dan strata 2. Analisis yang digunakan untuk mengklasifikasikan stasiun-stasiun tersebut adalah metode Cluster Analysis atau metode analisis kelompok.

Cluster Analysis digunakan untuk mengelompokkan unit-unit statistik ke dalam kelompokkelompok yang homogen dari sejumlah variabel atau karakter yang kita pelajari (Bengen 2000). Metode ini bersifat deskriptif di mana tidak ada satu pun variabel mempunyai peranan yang lebih penting dari variabel lain. Cluster Analysis dibentuk berdasarkan euclidien distance di antara lokasi-lokasi sampling, dengan rumus:

$$
\mathrm{D}(\mathrm{j}, \mathrm{k})(\mathrm{h})=\alpha 1 \mathrm{D}(\mathrm{j}, \mathrm{h})+\alpha 2 \mathrm{D}(\mathrm{k}, \mathrm{h})+\beta \mathrm{D}(\mathrm{j}, \mathrm{k})
$$

$\mathrm{D}(\mathrm{j}, \mathrm{k})$ adalah distance antara nilai sampling unit (SU) $\mathrm{j}$ dan $\mathrm{k}$; serta $\alpha$ dan $\beta$ adalah nilai koefisien tertentu dari distance tertentu.

\section{INPUT}

\section{OUTPUT}

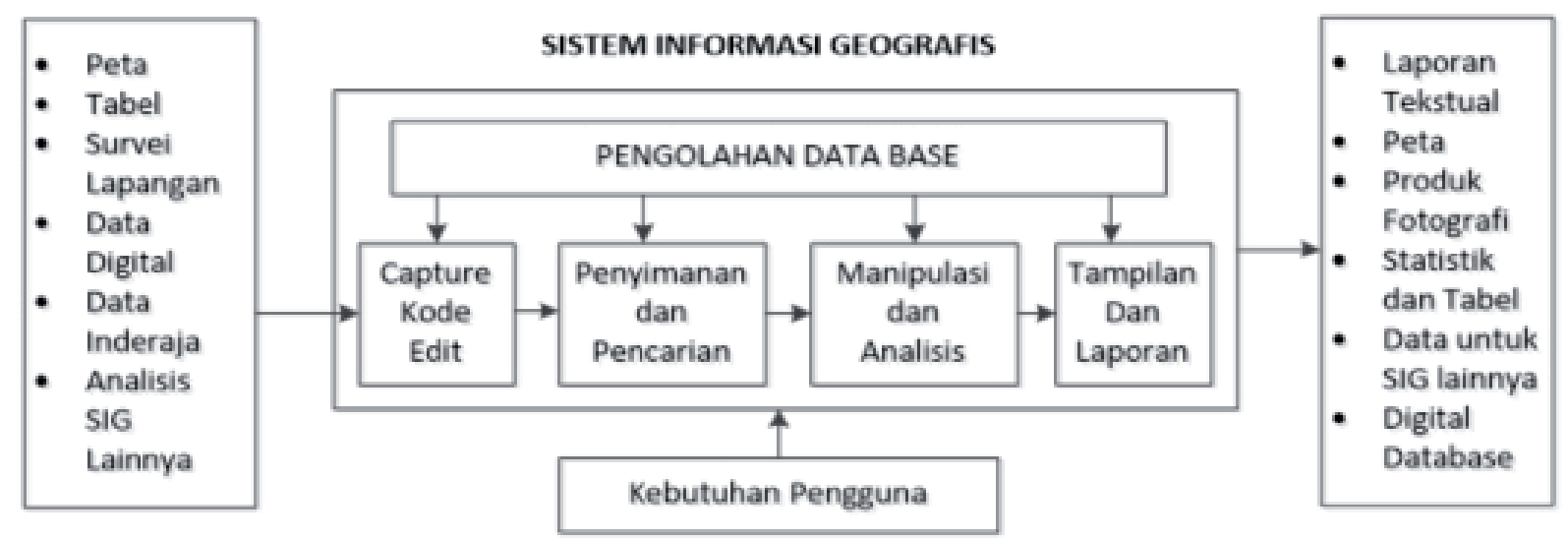

Gambar 1 Diagram Sistem untuk Ilustrasi Sistem Informasi Geografis (Sumber: Meaden dan Kapetsky 1991) 


\section{HASIL DAN PEMBAHASAN}

\section{Potensi Perikanan di Selat Sunda pada Bulan Mei}

Nilai rata-rata terbesar dari seluruh kedalaman perairan terdapat pada area sebelah timur Pulau Rakata Kecil dengan kelimpahan ikan maksimum sebesar $8.709 \mathrm{ikan} / 1000 \mathrm{~m}^{3}$, rata-rata kelimpahan ikan setiap kedalaman pengambilan contoh adalah sebesar $4.148 \mathrm{ikan} / 1000 \mathrm{~m}^{3}$ yang termasuk ke dalam kategori cukup ikan (Gambar 2). Secara keseluruhan, rata-rata kelimpahan ikan pada bulan Mei diketegorikan dengan kondisi cukup ikan.

\section{Potensi perikanan di Selat Sunda pada bulan Juni}

Nilai rata-rata terbesar dari seluruh kedalaman perairan terdapat pada area sebelah timur laut pulau Panaitan yaitu dengan kelimpahan ikan maksimum sebesar $12.287 \mathrm{ikan} / 1000 \mathrm{~m}^{3}$, rata-rata kelimpahan ikan setiap ke dalaman pengambilan contoh adalah sebesar $5.266 \mathrm{ikan} / 1000 \mathrm{~m}^{3}$ yang termasuk ke dalam kategori melimpah (Gambar 3). Secara keseluruhan, rata-rata kelimpahan ikan pada bulan Juni termasuk ke dalam kategori melimpah.

\section{Potensi perikanan di Selat Sunda pada bulan Juli}

Dilihat dari Gambar 4, dapat diketahui kelimpahan rata-rata maksimum berada di antara pulau Panaitan dan Tanjung Cukuredak sebesar $58.327 \mathrm{ikan} / 1000 \mathrm{~m}^{3}$. Kelimpahan rata-rata sebesar 18,392 ikan/1000 $\mathrm{m}^{3}$ dengan kategori sangat melimpah.

\section{Potensi perikanan di Selat Sunda pada bulan Agustus}

Dilihat dari rata-rata sebaran kelimpahan ikan untuk seluruh ke dalaman pada bulan Agustus (Gambar 5), kelimpahan maksimum terdapat pada stasiun 28 yang berada di wilayah Pulau Tabuan dan Pulau Sertung dengan densitas sebesar $13.181 \mathrm{ikan} / 1000 \mathrm{~m}^{3}$ yang termasuk dalam kategori sedang. Kelimpahan rata-rata sebesar $3.114 \mathrm{ikan} / 1000 \mathrm{~m}^{3}$ dengan kategori melimpah. Pada Gambar 26 terlihat bahwa kelimpahan terbesar ada pada ke dalaman 4-24 m diikuti oleh ke dalaman 22-44 m. Kelimpahan minimum terdapat pada kedalaman 64-84 m.

Fluktuasi potensi perikanan dapat diketahui dengan tepat jika pengambilan data akustik yang diharapkan dapat mewakili kondisi yang sebenarnya dari pengambilan data tersebut. Antara bulan Mei hingga Agustus dapat dibandingkan keseluruhan kedalaman yang menjadi pengamatan, dari kedalaman 4-84 m. Hal ini menjadi pertimbangan karena adanya perbedaan suhu, tekanan, dan salinitas. Ikan akan cenderung melimpah pada lapisan atas dan akan menipis pada lapisan bawah. Hal ini sesuai dengan pernyataan Mac Lennan (1990) yang menyatakan bahwa target strength ikan sangat bervariasi karena dipengaruhi oleh waktu atau tingkah laku ikan atau kondisi fisik yang tidak diketahui sehingga pada saat survei populasi ikan tidak dianggap sebagai sesuatu yang konstan.

Perubahan densitas ikan pada empat bulan yang berbeda terlihat bahwa densitas terbesar terdapat pada bulan Juli yang merupakan musim timur dengan rata-rata kelimpahan ikan sebesar 18,392/1000 $\mathrm{m}^{3}$, kemudian diikuti oleh bulan Juni dengan kelimpahan rata-rata sebesar $5.266 \mathrm{ikan} / 1000 \mathrm{~m}^{3}$ yang merupakan musim timur. Hasil penelitian Supangat (2004) menyatakan pada bulan Juni (musim timur), sebaran temperatur permukaan berkisar antara $29,3-29,7^{\circ} \mathrm{C}$ yang merupakan suhu ideal bagi ikan pelagis dalam mencari makanan, serta suhu yang ideal pula untuk tumbuhnya berbagai jenis plankton. Lalu, diikuti oleh bulan Mei dengan rata-rata kelimpahan ikan sebesar $4.148 \mathrm{ikan} / 1000 \mathrm{~m}^{3}$ dan yang paling kecil adalah kelimpahan rata-rata pada bulan Agustus sebesar $3.113 \mathrm{ikan} / 1000 \mathrm{~m}^{3}$. Hasil penelitian Genisa (2003) yang meneliti tentang struktur komonitas ikan dan sebarannya di perairan Selat Sunda diketahui diketahui bahwa ikan yang terkumpul dari stasiun-stasiun pengamatan di Selat Sunda berjumlah 3.074 ekor, terdiri atas 49 jenis dan 27 famili. Jenis ikan yang dominan adalah Sthelophorus tri, Leiognathus elongatus, dan Therapon theraps. Sebaran jenis atau spesies disemua stasiun tidak merata. Indeks kekayaan jenis pada keempat stasiun tidak begitu besar perbedaannya. Potensi perikanan terbesar dapat berada pada bulan Juli yang merupakan musim timur. DISHIDROS TNI AL (1984) menyatakan bahwa pada musim timur angin tidak terlalu besar sehingga tinggi gelombang relatif rendah yang menyebabkan kelimpahan ikan masuk dalam kategori sangat melimpah dan cocok dijadikan musim tangkap.

\section{Pendugaan Wilayah Prioritas Penangkapan}

Data time series bulanan yang cukup banyak sangat diperlukan agar dapat mewakili kondisi potensi perikanan yang sebenarnya 
di Selat Sunda. Dengan demikian, penentuan prioritas penangkapan akan menjadi suatu hal yang sulit jika dilakukan dengan data yang terbatas. Pada penelitian ini, pendugaan prioritas wilayah penangkapan hanya didasarkan pada pengambilan data yang terbatas, yaitu bulan
Mei, Juni, Juli, dan Agustus. Dengan kata lain, pendugaan prioritas wilayah penangkapan akan digambarkan secara kasar, namun penelitian ini diharapkan dapat memberikan gambaran tentang fluktuasi kelimpahan ikan pada keempat bulan pengambilan contoh tersebut. Menurut

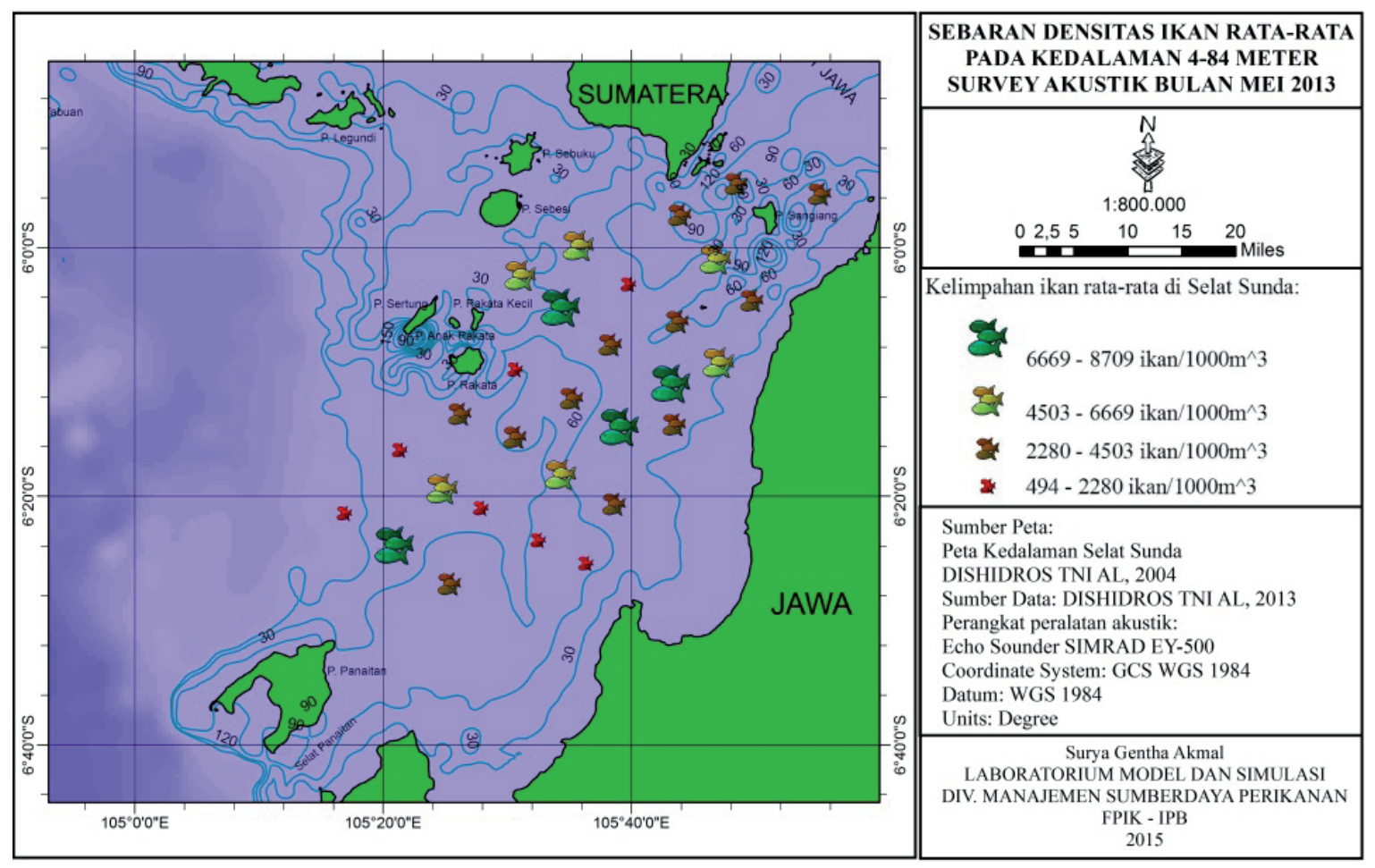

Gambar 2 Sebaran Densitas rata-rata ikan di bulan Mei pada ke dalaman 4-84 m
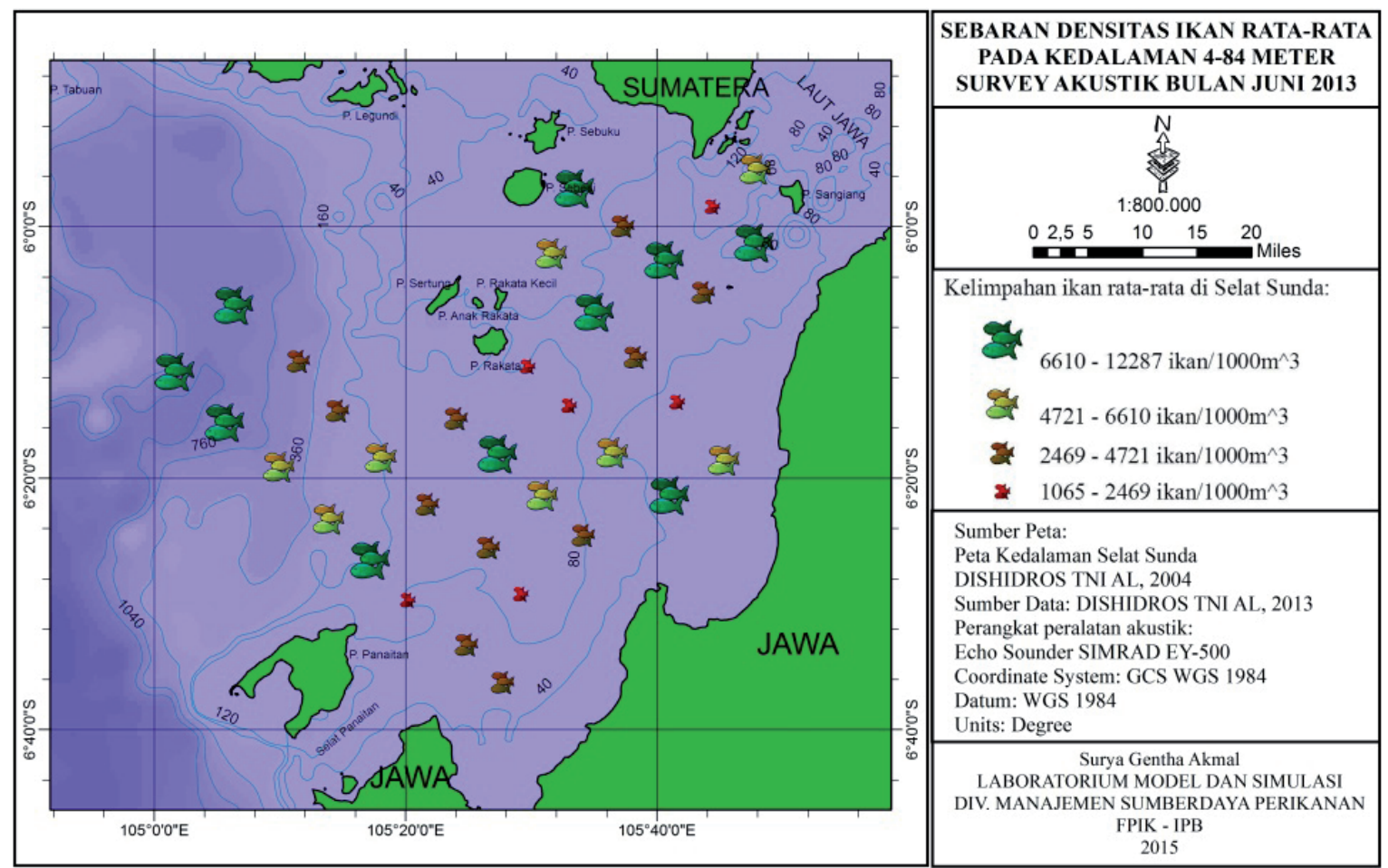

Gambar 3 Sebaran Densitas rata-rata ikan di bulan Juni pada ke dalaman 4-84 m 


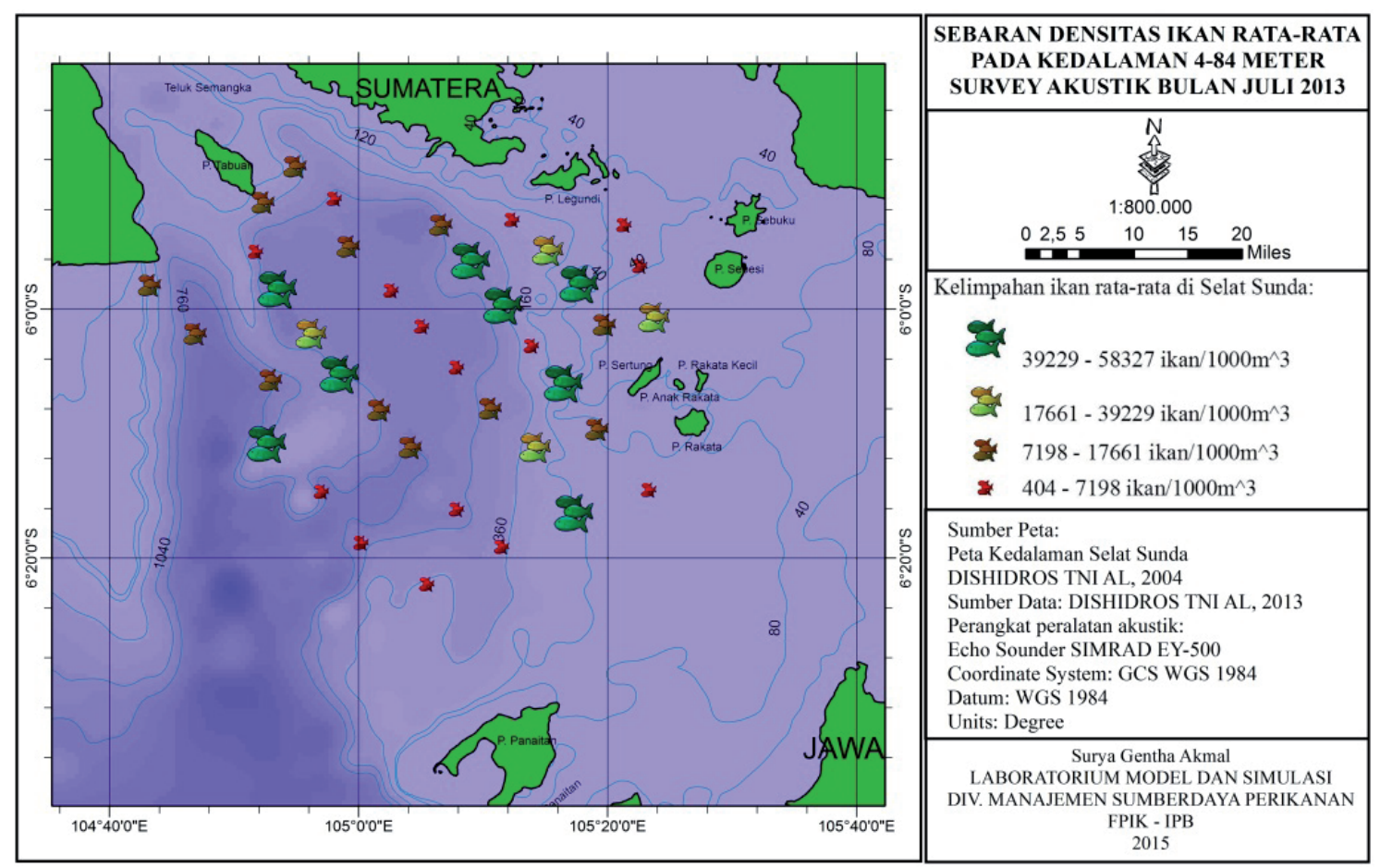

Gambar 4 Sebaran densitas rata-rata ikan di bulan Juli pada ke dalaman 4-84 m

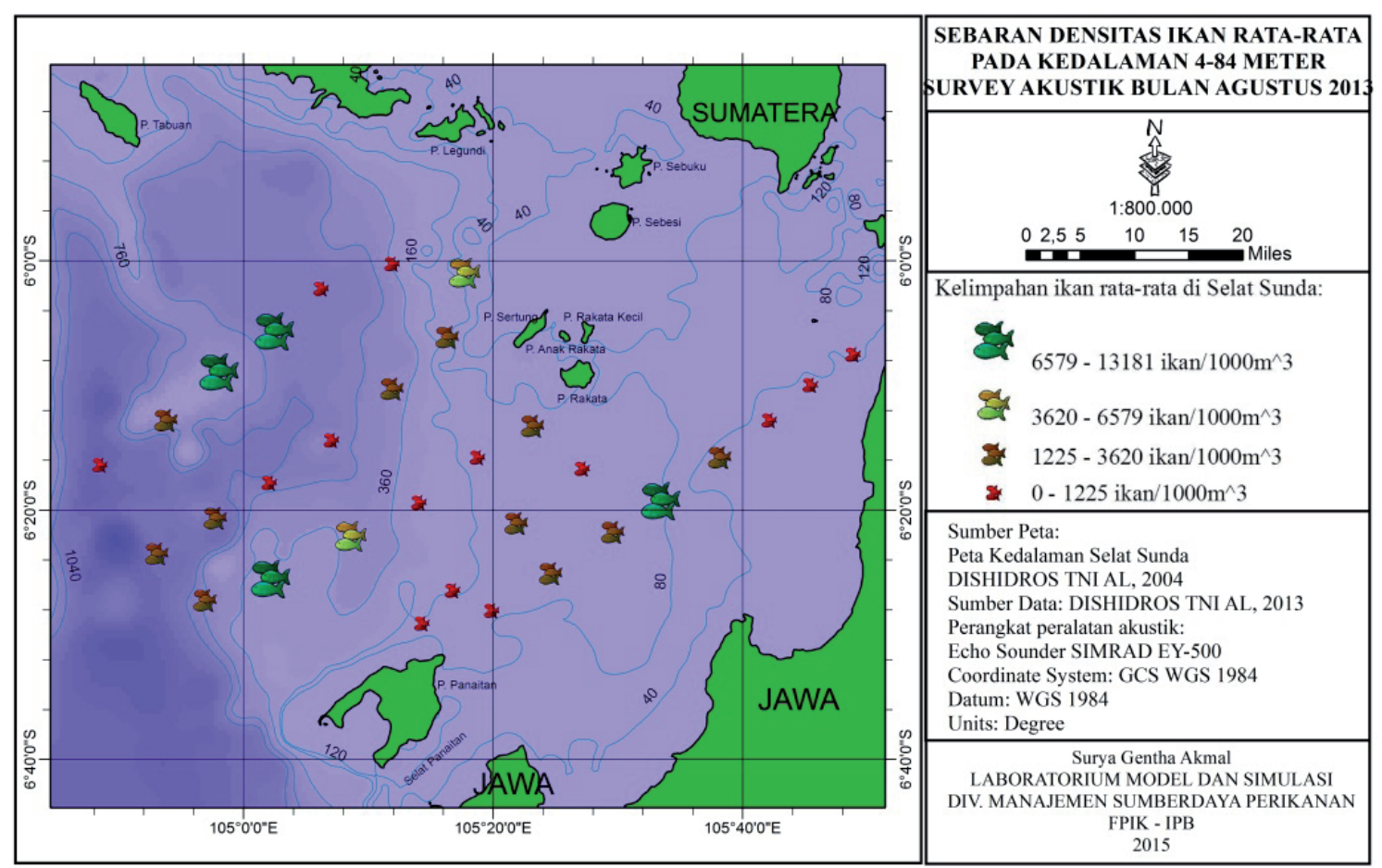

Gambar 5 Sebaran densitas rata-rata ikan di bulan Agustus pada ke dalaman 4-84 m

hasil wawancara dengan nelayan kecil yang beroperasi di Selat Sunda dan berada di pesisir barat Jawa (PPN Pelabuhan Ratu, PPP Labuan, PPP Karangantu), diketahui bahwa kebanyakan dari mereka menggunakan alat tangkap mini purse sine dan gillnet dalam menangkap ikan. Jenis alat tangkap ini menggunakan jaring sepanjang
250-350 m dan kedalaman jangkauan jaring hanya mencapai 40-50 m. Inilahyang menyebabkan kenapa pendugaan prioritas penangkapan hanya dilihat dari kedalaman $4 \mathrm{~m}$ hingga kedalaman $44 \mathrm{~m}$.

Klasifikasi untuk seluruh stasiun perekaman data dilakukan dengan menggunakan software Minitab, lalu stasiun-stasiun yang memiliki 
nilai kelimpahan yang saling berdekatan dapat dikelompokkan dengan metode cluster analisys. Hasil dari pengelompokan ini nantinya akan digunakan untuk menentukan prioritas wilayah penangkapan. Dari hasil penentuan prioritas wilayah penangkapan dengan yang hanya memfokuskan pada kedalaman dibawah $50 \mathrm{~m}$, diharapkan akan lebih bermafaat bagi masyarakat nelayan kecil.

\section{KESIMPULAN DAN SARAN}

\section{Kesimpulan}

Berdasarkan kelimpahan ikan di perairan Selat Sunda, diketahui puncak musim penangkapan adalah pada bulan Juli yang merupakan musim Timur. Daerah prioritas penangkapan pada bulan Juli berada di sekitar timur laut Pulau Panaitan dan lepas pantai Teluk Banten. Prioritas wilayah penangkapan dapat diduga berdasarkan kondisi nelayan yang beroperasi di perairan Selat Sunda yang kebanyakan memiliki kemampuan tangkap maksimum kurang dari $50 \mathrm{~m}$.

\section{Saran}

Perlu adanya data yang real time agar pendugaan potensi perikanan dan wilayah prioritas penangkapan menjadi lebih akurat. Jarak antarlokasi pengamatan dipersempit sehingga sumberdaya ikan di perairan dapat terdeteksi dan pendugaan potensi perikanan lebih representatif. Sangat disayangkan data yang berhasil didapatkan hanya terdiri atas empat bulan pengambilan data. Harapannya dengan data yang terbatas tersebut dapat memberikan gambaran kasar tentang fluktuasi potensi perikanan pada bulan-bulan yang berbeda (bulan Mei, Juni, Juli, dan Agustus).

\section{DAFTAR PUSTAKA}

Bengen D. 2000. Teknik Pengambilan Contoh dan Analisa Data Biofisik Sumberdaya Pesisir dan Lautan. PKSPL-IPB. Bogor. 87 hal.

DISHIDROS. 1984. Informasi Lingkungan Perairan Selat Sunda. Dinas HidroOseanografi TNI AL. Jakarta.

Genisa AS. 2003. Struktur komunitas ikan dan sebarannya di perairan Selat Sunda, Jawa Barat. Jurnal Ilmu Kelautan dan Perikanan Torani-UNHAS. Makasar. 13(3): 109-114.

Goodchild MF. 1993. The Stateof GIS for Environmental Problem Solving. In Goodchild, et al. Environmental Modelling with GIS. Oxford University Press, New York.

MacLennan DN. 1990. Acoustical Measurement of Fish Abundance. J.acoust. Soc.Am. 87(1): 1-15.

Meaden GJ dan Kapetsky JM. 1991. Geographical Information System and Remote Sensing in Inland Fisheries and Aquaculture. FAO Fisheries Technical Paper, No. 318. Rome. FAO. 262p.

Nurwandjedi. 1996. Penggunaan SIG untuk Pengelolaan Database Wilayah Pesisir. Makalah Pelatihan Perencanaan Wilayah Pesisir Secara Terpadu. PPLH-LP. IPB. Bogor.

Star and Estes. 1990. Geographyc Information System: An Introduction. Prentice Hall. New Jersey.

Supangat A, Wagey T, Burhanuddin S. 2004. Daya Dukung Kelautan dan Perikanan Tim Proyek Carrying Capacity Badan Riset Kelautan dan Perikanan. Jakarta: Badan Riset Kelautan dan Perikanan, Departemen Kelautan dan Perikanan. 